\title{
miR-145-5p reduces proliferation and migration of hepatocellular carcinoma by targeting KLF5
}

\author{
HAO LIANG ${ }^{1}$, HUIPING SUN ${ }^{2}$, JINFENG YANG $^{2}$ and CHUN YI ${ }^{3}$ \\ ${ }^{1}$ Clinical Laboratory, The Second Xiangya Hospital of Central South University, Changsha, Hunan 410011; \\ ${ }^{2}$ Department of Anesthesiology, Hunan Cancer Hospital, The Affiliated Cancer Hospital of Xiangya School of Medicine, \\ Central South University, Changsha, Hunan 410013; ${ }^{3}$ Department of Pathology, \\ Hunan University of Chinese Medicine, Changsha, Hunan 410208, P.R. China
}

Received November 2, 2015; Accepted May 3, 2017

DOI: $10.3892 / \mathrm{mmr} .2018 .8880$

\begin{abstract}
MicroRNAs (miRs) are important in hepatocellular carcinoma (HCC) progression. miR-145-5p acts as a tumor suppressor in certain malignancies, however, its role in HCC remains unclear. The present study aimed to perform a functional analysis of miR-145-5p in HCC in order to elucidate its role in the pathogenesis of HCC. Reverse transcription-quantitative polymerase chain reaction (RT-qPCR) was performed to analyze tissue and cellular expression of miR-145-5p in HCC. Following miRNA mimics transfection, cell viability, apoptosis and cells migration were determined by Cell Counting kit-8, Annexin V-FITC/propidium iodide staining and Transwell analyses. The target of miR-145-5p was analyzed by luciferase reporter assay and western blot analysis. It was observed that miR-145-5p was significantly decreased in HCC tissues and cell lines. Overexpression of miR-145-5p significantly increased apoptosis, reduced cell proliferation and suppressed HCC cell migration. Kruppel-like factor 5 (KLF5) is regarded as a target of miR-145-5p in HCC cells. In addition, KLF5 overexpression partially attenuated the tumor suppressive effects of miR-145-5p. KLF5 expression was negatively associated with levels of miR-145-5p in HCC tissues. The present study demonstrated that miRNA-145-5p may, by targeting KLF5, partially suppress HCC cell growth and motility. The results of the present study suggested that miRNA-145-5p alteration in HCC may serve a role in the progression of HCC.
\end{abstract}

\footnotetext{
Correspondence to: Dr Chun Yi, Department of Pathology, Hunan University of Chinese Medicine, 300 Xueshi Road, Changsha, Hunan 410208, P.R. China

E-mail: yc_1227@163.com
}

Key words: miR-145-5p, hepatocellular carcinoma, Kruppel-like factor 5, proliferation

\section{Introduction}

Hepatocellular carcinoma (HCC) is one of the most frequently occurring malignant tumors globally (1). In the past decade, patients with HCC have had to endure a high incidence of recurrence and metastasis; a 5-year recurrence rate of 75-100\% is reported (2). Surgical resection, liver transplantation and radiofrequency ablation may provide a cure for certain early stage patients however, due to the asymptomatic nature of $\mathrm{HCC}$, the majority of patients are diagnosed at an advanced stage (3). The molecular mechanisms involved in HCC remain poorly understood. The development of novel strategies to further the understanding of HCC is required. Alterations in molecular expression in HCC have been extensively investigated. Dysregulated gene expression has been observed during the development of HCC (4). Kruppel-like factor 5 (KLF5), a zinc finger protein that belongs to the KLF family, is a transcription factor that binds the epidermal growth factor response element (5). KLF5 was recently demonstrated to be upregulated in metastatic HCC (6). Additionally, increased expression of KLF5 promotes cell proliferation and inhibits apoptosis (7). However, the mechanism of aberrant KLF5 expression remains unclear.

As a family of endogenous, small non-coding RNAs (20-25 nucleotides in length), microRNAs (miRNAs) post-transcriptionally regulate the expression of complementary target mRNA in eukaryotes, which influences several biological processes, including cell infection, development, immunity and carcinogenesis $(8,9)$. miRNA expression profiles reveal that numerous miRNA signatures exist in various different cancer types (10-13). It is indicated that miRNA signatures may be predictive for cancer prognosis, classification and response to therapy $(14,15)$. Emerging evidence indicates that miRNAs have significant roles in the development of $\mathrm{HCC}$, and certain tumor suppressive miRNAs in HCC have already been identified (16). Decreased expression of miRNA (miR)-145-5p in several cancer types, including prostate (17) and liver cancer (18), has been previously reported. The present study determined the expression of miR-145-5p in HCC and miR-145-5p overexpression, through use of miRNA mimics, was observed to inhibit the proliferation and metastasis of HCC cells. Furthermore, the present study identified KLF5 as 
a target of miR-145-5p in HCC cells. The current study also demonstrated the association between miR-145-5p and KLF5.

\section{Materials and methods}

HCC tissues and cell lines. HCC tissues and paired normal liver tissues were obtained from 25 patients with primary HCC at The Second Xiangya Hospital of Central South University (Changsha, China). The Ethics Committee of The Second Xiangya Hospital of Central South University approved this study after written informed consent was obtained from each patient. Details of the patients are presented in Table I. L02 normal human liver cell line and HuH-7, HepG2 and SK-Hep-1 HCC cell lines were obtained from American Type Culture Collection (Manassas, VA, USA). The cells were cultured in Dulbecco's modified Eagle's medium (Gibco; Thermo Fisher Scientific, Inc., Waltham, MA, USA), which was supplemented with $10 \%$ fetal bovine serum (FBS; Gibco; Thermo Fisher Scientific) and at $37^{\circ} \mathrm{C}$ in a $5 \% \mathrm{CO}_{2}$ incubator.

RNA isolation \& reverse transcription-quantitative polymerase chain reaction (RT-qPCR). By using TRIzol or miRNeasy Mini kit (Qiagen, Inc., Valencia, CA, USA), RNA was extracted, followed by reverse transcription using cDNA Reverse Transcription kit (Qiagen, Inc.). RT-qPCR was performed using SYBR-Green Master Mix (cat. no. RR420A; Takara Biotechnology Co., Ltd., Dalian, China) on LightCycler ${ }^{\circledR} 480$ System (Roche Diagnostics GmbH, Mannheim, Germany). miR-145-5p primers were purchased from Sigma-Aldrich (Merck KGgA, Darmstadt, Germany; cat. no. MIRAP00180). The reaction system included $2.5 \mu \mathrm{l}$ cDNA (1:20 dilution by double-distilled water), $10 \mu 1$ reaction mixture (Qiagen, Inc.), $2.0 \mathrm{mM}$ forward primer, and $2.0 \mathrm{mM}$ reverse primer, respectively. The experiment was repeated three times. The primers of KLF5 were as follows: 5'-CTTCCACAACAG GCCACTTACTT-3' (forward) and 5'-AGAAGCAATTGT AGCAGCATAGGA-3' (reverse). GAPDH primers were as follows: 5'-GAAGGTGAAGGTCGGAGTC-3' (forward) and 5'-GAAGATGGTGATGGGATTTC-3' (reverse). The cycling conditions were as follows: Initial denaturation step at $95^{\circ} \mathrm{C}$ for $5 \mathrm{~min}$, followed by 40 cycles of $95^{\circ} \mathrm{C}$ for $30 \mathrm{sec}$, and $60^{\circ} \mathrm{C}$ for $30 \mathrm{sec}$. Relative expression was calculated using the $2^{-\Delta \Delta \mathrm{Ca}}$ method and levels were normalized to the reference gene, GAPDH.

miRNA mimics and construction of expression vectors. miR-145-5p mimics (cat. no. miR30000157-1-2), which mimic endogenous miRNA, and inhibitors (cat. no. miR20000437-1-2) were obtained from Guangzhou RiboBio Co., Ltd. (Guangzhou, China). The control group was transfected with an empty pcDNA3.1 vector (Invitrogen; Thermo Fisher Scientific, Inc.). The entire coding region of KLF5 was amplified and restriction enzymes, NotI and EcoRI (New England BioLabs, Inc., Ipswich, MA, USA), were employed to insert the KLF5 fragment into the mammalian expression vector, pcDNA3.1. The primers were as follows: 5'-GGGCGGCCATGGCTACAAGGGTGCTGAG CATGAG-3' (forward); 5'-GGGAATTCTCAGTTCTGG TGCCTCTTCATATGCAGGGCC-3' (reverse). The control involved empty vectors without inserted fragments. For the luciferase reporter, Dual-Luciferase Reporter Assay System (Promega Corporation, Madison, WI, USA) was used and the 3'-untranslated region (3'-UTR) target sequence from KLF5 was amplified and subsequently inserted into psiCHECK-2 vector (Promega Corporation).

Cell viability and apoptosis analysis. Using Cell Counting kit-8 (CCK-8; Dojindo Molecular Technologies, Inc., Rockville, MD, USA), cell proliferation rates were measured. Cells $\left(1 \times 10^{5}\right.$ cells/well) were seeded before incubation with mimics/inhibitors (50 $\mathrm{nM}$ mimics and $200 \mathrm{nM}$ inhibitors). The transfection was performed using Lipofectamine ${ }^{\circledR} 2000$ (Invitrogen; Thermo Fisher Scientific, Inc., Waltham, MA, USA). The mimics and inhibitors were combined with $10 \mu$ l Lipofectamine ${ }^{\circledR} 2000$ diluted in $250 \mu$ l Opti-MEM I (Invitrogen; Thermo Fisher Scientific, Inc.) and incubated for $30 \mathrm{~min}$. The mixture was then added to cells which attained $90 \%$ confluence in the 96-well plates. After 24, 48, and $72 \mathrm{~h}$ transfection, $10 \mu \mathrm{lCCK}-8$ reagent was added to each well. The optical density at $450 \mathrm{~nm}$ was determined using a Multiskan MK3 microplate reader (Thermo Fisher Scientific, Inc.). In order to analyze apoptosis, cells were harvested and washed in ice-cold PBS and were then fixed in $70 \%$ ice-cold ethanol at $4^{\circ} \mathrm{C}$ for $1 \mathrm{~h}$. Cells were incubated with $20 \mu \mathrm{g} / \mathrm{ml}$ propidium iodide and Annexin V-APC (Sigma-Aldrich; Merck $\mathrm{KGgA}$ ) for a period of $20 \mathrm{~min}$ at room temperature, and were then analyzed using Fluorescence Activated Cell Sorter (BD Biosciences, Franklin Lakes, NJ, USA). The cells were analyzed by CellQuest software (version 3; BD Biosciences).

Cells migration analysis. A total of $48 \mathrm{~h}$ following transfection, cell migration was evaluated using a Transwell chamber (EMD Millipore, Billerica, MA, USA). Transwell inserts were pre-coated with Matrigel (BD Biosciences) and were placed in the upper compartment prior to cell seeding. Cells $\left(5 \times 10^{4}\right)$ were seeded in the upper chamber without FBS. The lower chamber was then filled with medium that was supplemented with 10\% FBS (FBS; Gibco; Thermo Fisher Scientific, Inc.). Migratory cells on the bottom surface were then fixed by $4 \%$ paraformaldehyde solution for $20 \mathrm{~min}$ at room temperature, and stained with $0.1 \%$ crystal violet for $15 \mathrm{~min}$ at room temperature. From each membrane, the number of migrated cells in four random fields were counted by a microplate reader (Bio-Rad Laboratories, Inc., Hercules, CA, USA). Experiments were conducted in triplicate.

Western blot analysis. HCC and control tissues were lysed using radio immunoprecipitation assay buffer (cat. no. P0013B; Beyotime Institute of Biotechnology, Haimen, China) $48 \mathrm{~h}$ following transfection. Protein concentration was determined using a bicinchoninic acid protein assay kit (Beyotime Institute of Biotechnology). Then, for each sample, $20 \mu \mathrm{g}$ extracted protein was separated on a $10 \%$ SDS-PAGE gel (cat. no. P0012A, Beyotime Institute of Biotechnology) at $90 \mathrm{~V}$ for $25 \mathrm{~min}$ followed by $120 \mathrm{~V}$ for $1.5 \mathrm{~h}$ and transferred to polyvinylidene difluoride membranes (EMD Millipore). The transfer was performed using a Mini Trans-Blot Transfer Cell (Bio-Rad Laboratories, Inc.) at $4^{\circ} \mathrm{C}$ for $1.5 \mathrm{~h}$ at a constant 
Table I. Characteristics patients with hepatocellular carcinoma $(\mathrm{n}=25)$.

\begin{tabular}{lc}
\hline Characteristic & Number of patients \\
\hline Age (years) & \\
$<50$ & 10 \\
$\geq 50$ & 15 \\
Sex & \\
Male & 17 \\
Female & 8 \\
Hepatitis history & \\
Yes & 11 \\
No & 14 \\
Liver cirrhosis & \\
Yes & 13 \\
No & 12 \\
Tumor diameter (cm) & \\
$<5$ & 17 \\
$\geq 5$ & 8 \\
Tumor differentiation grade & \\
I+II & 18 \\
III+IV & 7 \\
\hline
\end{tabular}

voltage setting of $100 \mathrm{~V}$. The membranes were blocked using 4\% non-fat dry milk in tris-buffered saline (TBS) with Tween-20 (Sigma-Aldrich; Merck KGgA) at room temperature for $30 \mathrm{~min}$. Membranes were then incubated with rabbit anti-human KLF5 polyclonal antibody (1:500; cat. no. ab24331) and rabbit anti-human GAPDH polyclonal antibody (1:1,000; cat. no. ab9485; both Abcam, Cambridge, MA, USA) overnight at $4^{\circ} \mathrm{C}$. Subsequently, horseradish peroxidase-labeled goat anti-rabbit $\operatorname{IgG}$ secondary antibody (1:2,000; cat. no. ab7090; Abcam) was incubated at $37^{\circ} \mathrm{C}$ for $1 \mathrm{~h}$ with the membranes and protein bands were visualized with the enhanced chemiluminescence system (EMD Millipore). Experiments were conducted in triplicate. The relative expression of protein was calculated by densitometric analysis using ImageJ software version 2.0.0 (National Institutes of Health, Bethesda, MD, USA).

Luciferase reporter assay. HepG2 cells $\left(1 \times 10^{5}\right.$ cells/well) were cultured in a 24-well plate and incubated for $24 \mathrm{~h}$. The cells were divided into four groups: i) miRNA negative control (cat. no. B04001; Shanghai GenePharma Co., Ltd., Shanghai, China) and wild-type 3'UTR of KLF5 group; ii) miR-145-5p mimic and wild-type 3 'UTR of KLF5 group; iii) miRNA negative control and mutant 3'UTR of KLF5 group; and iv) miR-145-5p mimic and mutant 3'UTR of KLF5 group. HepG2 cells were harvested $48 \mathrm{~h}$ after transfection. Using the Dual-Luciferase Reporter System (Promega Corporation), relative luciferase activity was evaluated and normalized to the activity of Renilla luciferase.

Statistical analysis. Data are presented as the mean \pm standard deviation, and were analyzed with SPSS 12.0 software (SPSS,
Inc., Chicago, IL, USA). Using Student's t-test or one-way analysis of variance followed Bonferroni's post-hoc test, quantitative variables were analyzed. Pearson's correlation coefficient was used to determine the correlation between KLF5 mRNA expression and miR-145-5p levels in HCC tissues. $\mathrm{P}<0.05$ was considered to indicate a statistically significant difference.

\section{Results}

miR-145-5p expression is decreased in HCC. RT-qPCR was used to determine the expression of miR-145-5p in $25 \mathrm{HCC}$ and matched non-tumor tissues. Compared with non-tumor tissues, the present study observed significantly decreased miR-145-5p level in HCC tissues $(\mathrm{P}<0.05$; Fig. 1A). The expression of miR-145-5p was significantly reduced in all three HCC cell lines compared with L02 normal human liver cells $(\mathrm{P}<0.05$; Fig. 1B).

miR-145-5p inhibits HCC cell proliferation and migration. Additionally, the present study observed that miR-145-5p suppressed the proliferation of HCC cells. RT-qPCR confirmed that transfection with the miR-145-5p mimic increased the expression of miR-145-5p (P<0.05; Fig. 2A). Following transfection with miR-145-5p or control mimics in HepG2 cells, the biological effect of miR-145-5p on the progression of HCC was determined by CCK- 8 assay. The CCK- 8 assay indicated that overexpression of miR-145-5p, induced by miR-145-5p mimics, significantly suppressed the cell proliferation rate after $48 \mathrm{~h}$ $(\mathrm{P}<0.05$; Fig. 2B). A significant increase in the percentage of apoptotic cells in miR-145-5p-overexpressing HepG2 cells was observed when compared with control HepG2 cells $(\mathrm{P}<0.05$; Fig. 2C). In addition, miR-145-5p or control mimics were transfected into HepG2 cells to determine the effect of miR-145-5p on motility of HCC cells, and migration assays were conducted. Overexpression of miR-145-5p significantly inhibited the migratory capabilities of HepG2 cells $(\mathrm{P}<0.05$; Fig. 3A and B).

KLF5 is a direct target of miR-145-5p. In order to determine the target of miR-145-5p in HCC, TargetScan 7.0 (www.targetscan.org) was used. It was demonstrated that KLF5 is a potential target of miR-145-5p (Fig. 4A). Results of the luciferase activity assay suggested that miR-145-5p overexpression significantly inhibited the luciferase activity of the WT 3'-UTR of KLF5 in HepG2 cells compared with the control $(\mathrm{P}<0.05$; Fig. 4B). In addition, miR-145-5p overexpression significantly suppressed KLF5 protein expression $(\mathrm{P}<0.05)$, while miR-145-5p inhibition did not change KLF5 protein expression compared with the control (Fig. 4C and D).

Overexpression of KLF5 reduces the tumor suppressive effects of miR-145-5p. Transfection of the KLF5 vector increased KLF5 expression significantly ( $\mathrm{P}<0.05$; Fig. 5A). Furthermore, KLF5 overexpression weakened the tumor suppressive effect of miR-145-5p in HepG2 cells (Fig. 5B). Additionally, the migration of HepG2 cells was significantly reduced by miR-145-5p compared with the control $(\mathrm{P}<0.05)$, while KLF5 overexpression reversed these suppressive effects (Fig. 5C and D). 

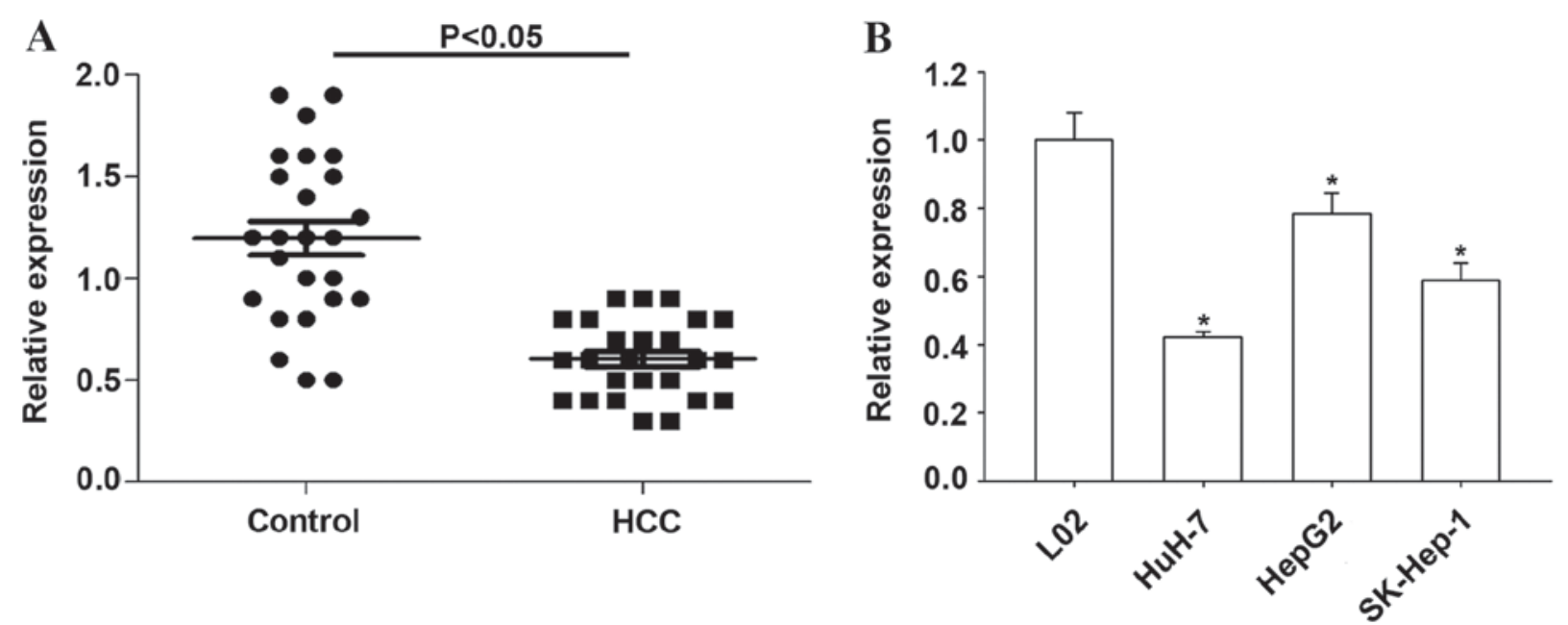

Figure 1. Relative miR-145-5p expression in HCC and controls. (A) Expression of miR-145-5p was measured by reverse transcription-quantitative polymerase chain reaction in HCC and normal liver tissue from 25 patients with primary HCC. (B) Reduced expression of miR-145-5p was observed in HuH-7, HepG2 and SK-Hep-1 HCC cell lines, compared with L02 normal human liver cell line. ${ }^{*} \mathrm{P}<0.05$ vs. L02 cell line. HCC, hepatocellular carcinoma; miR, microRNA.

A

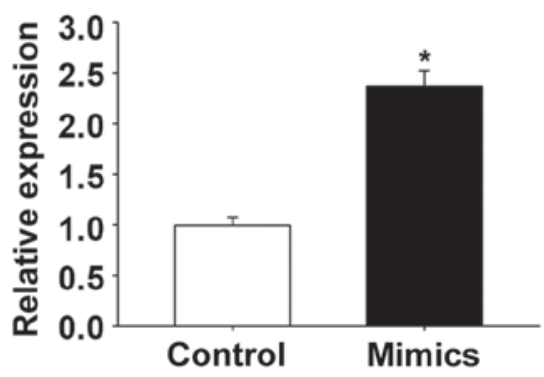

B

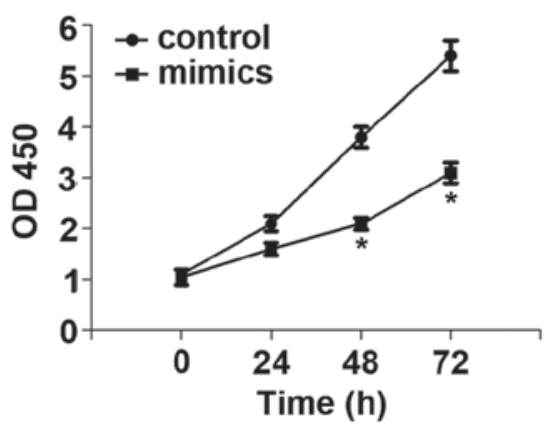

C

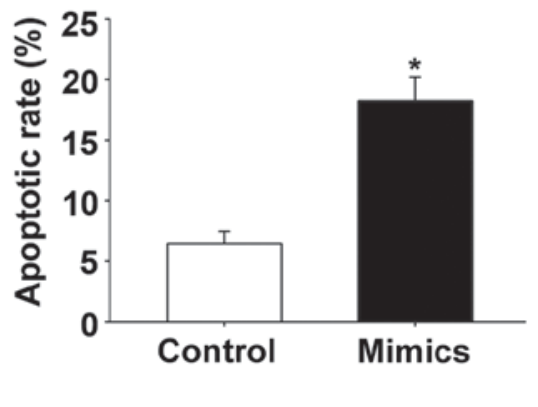

Figure 2. miR-145-5p reduces proliferation of hepatocellular carcinoma cells. (A) Reverse transcription-quantitative polymerase chain reaction indicated that mimic transfection led to miR-145-5p overexpression compared with control. (B) CCK-8 assay determined that mimic transfection reduced cell proliferation. (C) Levels of cellular apoptosis increased following mimic transfection compared with the control. "P<0.05 vs. control. miR, microRNA.

A

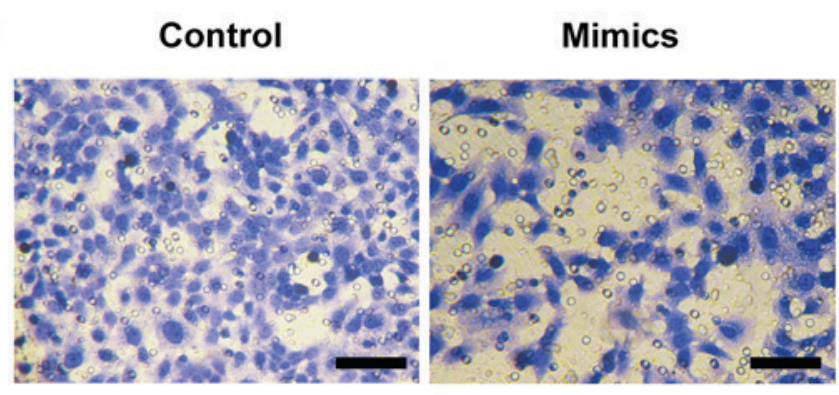

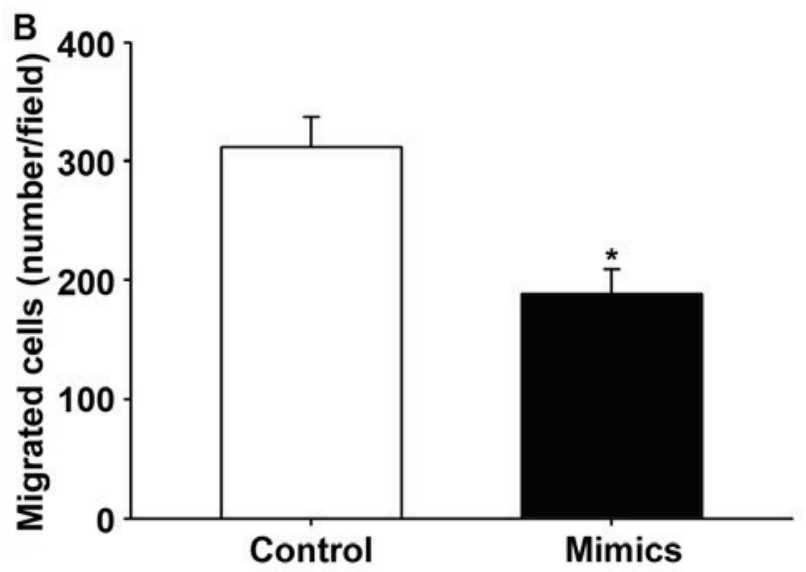

Figure 3. miR-145-5p inhibits migration of HCC cells. (A) Transwell assay of HepG2 cells with control or miR-145-5p transfection; scale bar, $50 \mu \mathrm{m}$. (B) In vitro migration of HCC cells with control or miR-145-5p transfection. "P<0.05 vs. control. miR, microRNA; HCC, hepatocellular carcinoma.

miR-145-5p and KLF5 are negatively correlated in HCC. The relative expression of KLF5 was detected in 25 non-tumor tissues and HCC tissues. The results indicated that, in HCC tissues, KLF5 mRNA levels were significantly increased compared with non-tumor tissues $(\mathrm{P}<0.05$; Fig. 6A). In addition, the present study observed that KLF5 mRNA expression was inversely correlated with miR-145-5p levels in HCC tissues ( $\mathrm{r}=-0.45)$ (Fig. 6B). 
A

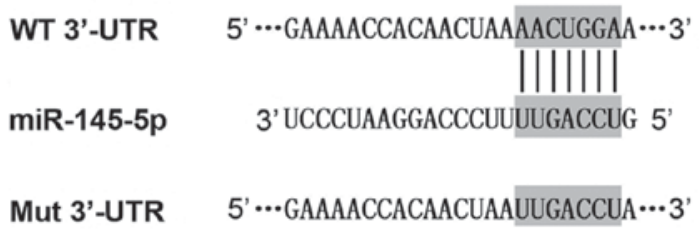

C
B

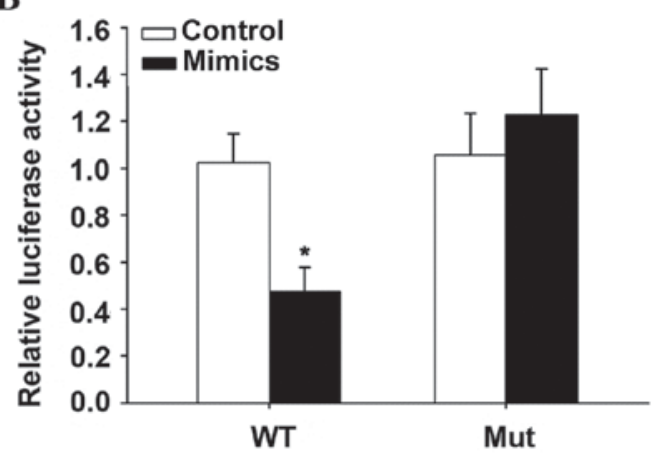

D

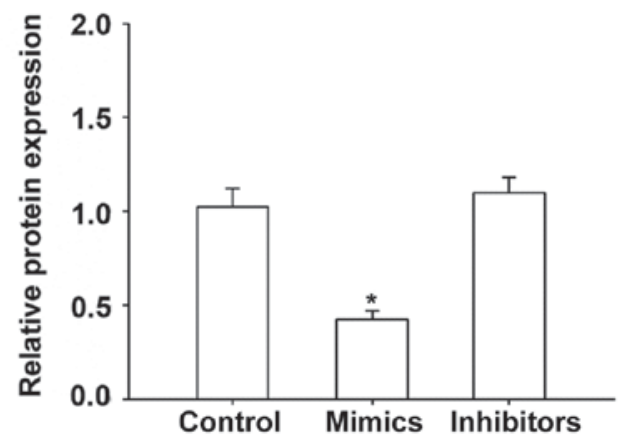

Figure 4. Target confirmation of miR-145-5p. (A) Target prediction by TargetScan 7.0 and the WT or Mut sequences of 3'-UTR from KLF5 mRNA. (B) Luciferase activity of WT or Mut co-transfected with control or miR-145-5p mimics. (C) Protein expression levels of KLF5 in HepG2 cells following transfection with miR-145-5p mimics or inhibitors, or control, by western blot. (D) Relative protein expression levels of KLF5 in HepG2 cells following transfection with miR-145-5p mimics or inhibitors, or control, calculated by grey mean value of binding using Image J software. "P<0.05 vs. control. miR, microRNA; WT, wild-type; Mut, mutant; UTR, untranslated region; KLF5, Kruppel-like factor 5.

\section{Discussion}

HCC has one of the highest mortality rates despite significant improvements in diagnosis and treatment in recent years (19). Although the mechanisms involved in HCC have been previously demonstrated, the involvement of epigenetic regulation remains predominantly unknown (20). As miRNAs are the most promising components of the epigenetic pathway in terms of targets for the development of novel therapeutic approaches, understanding the role of miRNA in HCC is essential. It is currently known that multiple miRNAs are involved in $\mathrm{HCC}$ development and progression. It has previously been observed that several miRNAs have aberrant expression in HCC and it is thought that these miRNAs may be used as prognostic indicators in HCC (21). miR-145-5p is a novel miRNA that is suggested to be implicated in cancer treatment and carcinogenesis. Downregulation of miR-145-5p has been reported in prostate cancer (17). Additionally, miR-145-5p was downregulated in prostate cancer (22), lung cancer (23) and colorectal cancer (24), indicating that miR-145-5p may have tumor suppressive effects. Expression levels of miR-145-5p were inversely associated with the proliferation of prostate cancer cells. Furthermore, in embryonic stem cells, by targeting the 3'UTR of SRY-box 2 mRNA, miR-145-5p suppresses self-renewal of human embryonic stem cells (17). Thus, investigation of miR-145-5p provides novel insight into the molecular mechanisms of cancer progression and carcinogenesis. The present study aimed to analyze the effects of miR-145-5p on HCC and to identify the potential target genes of miR-145-5p in order to study the molecular mechanism behind its role in $\mathrm{HCC}$ oncogenesis. Expression of endogenous miR-145-5p in $25 \mathrm{HCC}$ tissues was significantly downregulated. Similarly, miR-145-5p was downregulated in HCC cell lines, including HuH-7, HepG2 and SK-Hep-1, compared with the L02 normal liver cell line. Additionally, overexpression of miR-145-5p decreased proliferation rate and induced apoptosis in HCC cells. Transwell analysis indicated that miR-145-5p inhibited migration of HCC cells. This evidence suggested that downregulation of miR-145-5p may lead to increases in the proliferation, migration and aggression of HCC. The current study was extended to identify the potential targets of miR-145-5p in HCC cells. In silico bioinformatics analyses demonstrated that the 3'UTR of KLF5 is one potential target of miR-145-5p. In vivo and in vitro results demonstrated that KLF5 expression levels were significantly decreased in HCC cells overexpressing miR-145-5p. It is regarded that KLF5 is highly expressed in HCC tissues compared with healthy control tissues. The involvement of KLF5 in tumor progression has also been demonstrated in breast (25), intestinal (26), esophageal (27) and gastric cancer (28). The current study proposes that miR-145-5p is an important regulator of KLF5 since miR-145-5p overexpression in HCC cells reduced KLF5 expression. Decreased levels of miR-145-5p may be a key step in the pathogenesis of HCC. It is possible that miRNAs regulate several genes, by targeting the 3 'UTR of mRNA, and the subsequent changes in the expression of these target genes may participate in specific tissue development or cancer progression. The present study has identified that KLF5, a target of miR-145-5p, is a key marker gene in cancer. miR-145-5p may also contribute 

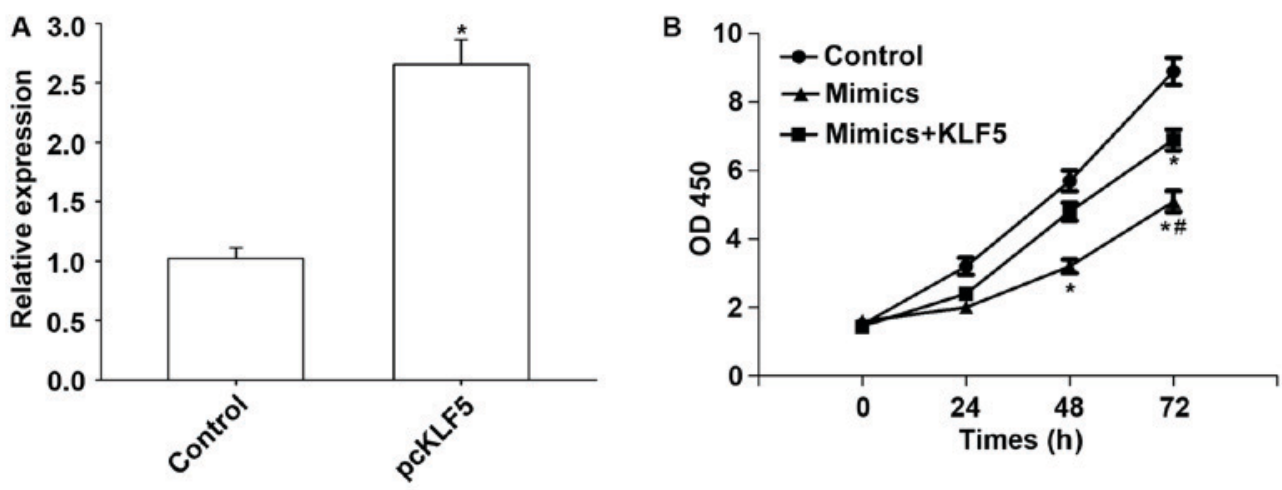

C
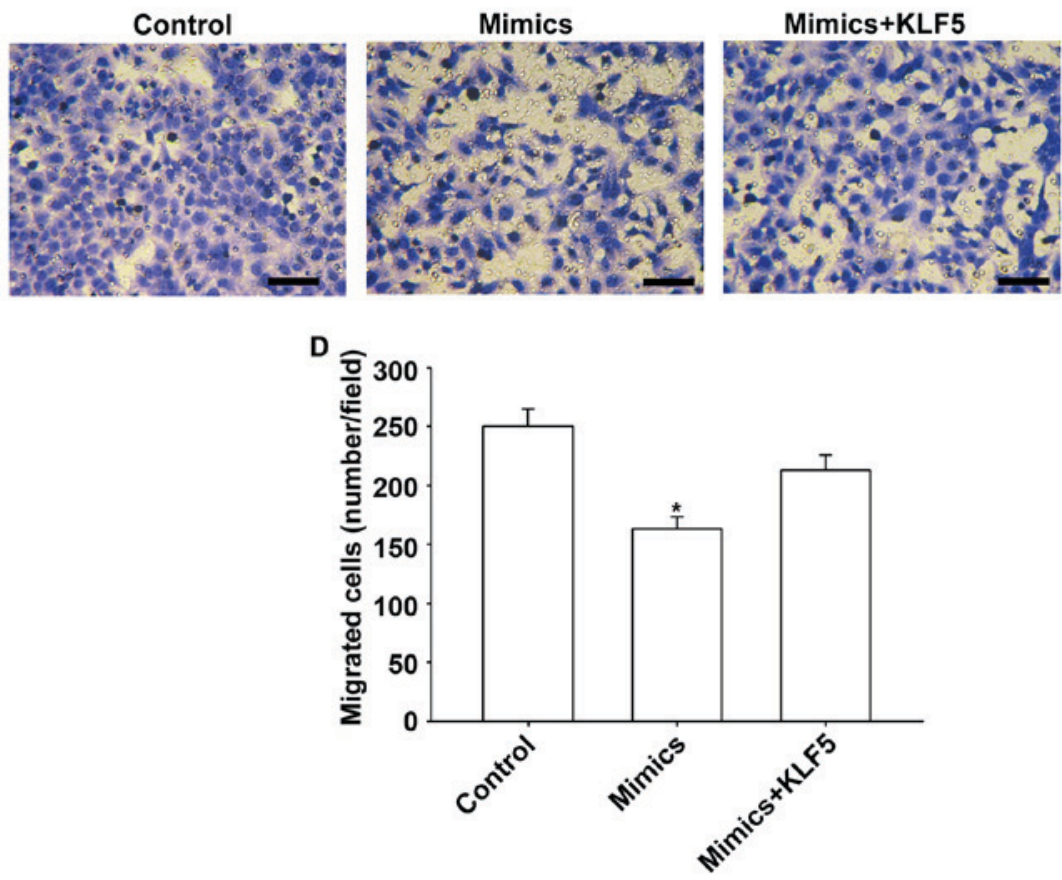

Figure 5. KLF5 overexpression reduces the tumor suppressive effects of miR-145-5p in HepG2 cells. (A) Expression of KLF5 after transfection with control or pc-KLF5. (B) Cell proliferation in cells transfected with control and miR-145-5p mimics with/without pc-KLF5 transfection. (C) Transwell assay of HepG2 cells transfected with control and miR-145-5p mimics with/without pc-KLF5 transfection; scale bar, $50 \mu \mathrm{m}$. (D) In vitro migration of hepatocellular carcinoma cells transfected with control and miR-145-5p with/without pc-KLF5 transfection; number of migrated cells per field. " $\mathrm{P}<0.05 \mathrm{vs.}$ control; ${ }^{\#} \mathrm{P}<0.05$ vs. mimcs+KLF5. KLF5, Kruppel like factor 5; miR, microRNA.

A

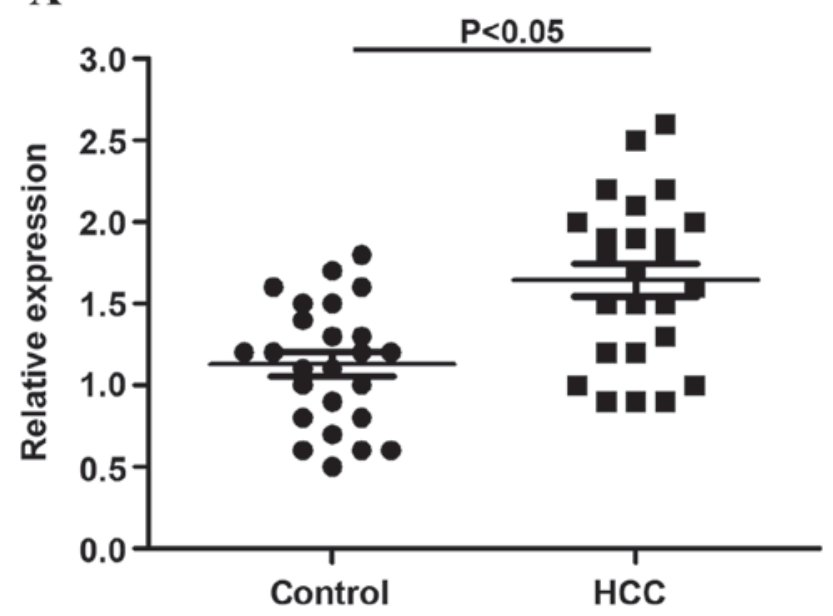

B

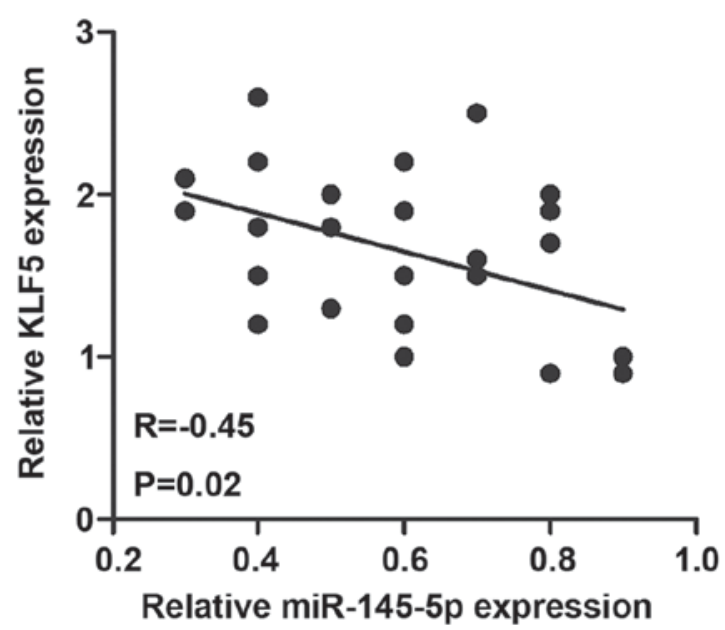

Figure 6. miR-145-5p is negatively correlated with KLF5 in HCC. (A) Higher relative expression of KLF5 was observed in HCC compared with normal control. (B) Correlation between relative expression of miR-145-5p and KLF5 in HCC as determined by reverse transcription-quantitative polymerase chain reaction. KLF5, Kruppel-like factor 5; miR, microRNA. 
to the dysregulation of other functional genes during tumor development. Thus, further studies should focus on the gene network of miR-145-5p in HCC and the miRNA profiles of circulating HCC tumor cells, which may demonstrate the roles of miRNA and improve the understanding of its function in HCC pathogenesis.

\section{Acknowledgements}

Not applicable.

\section{Funding}

The present study was supported by grants from the National Natural Science Foundation of China (grant no. 81302328) and the Science and Technology Department of Hunan province (grant no. 2013FJ4059).

\section{Availability of data and materials}

The datasets used and/or analyzed during the current study are available from the corresponding author on reasonable request.

\section{Authors' contributions}

HL and HS performed the experiments and wrote the paper. JY and CY designed the study and edited the manuscript. All authors read and approved the manuscript.

\section{Ethics approval and consent to participate}

The Ethics Committee of The Second Xiangya Hospital of Central South University approved this study and written informed consent was obtained from each patient.

\section{Consent for publication}

Not applicable.

\section{Competing interests}

The authors declare that they have no competing interests.

\section{References}

1. Bruix J and Sherman M; American Association for the Study of Liver Diseases: Management of hepatocellular carcinoma: An update. Hepatology 53: 1020-1022, 2011.

2. Yoo HY, Patt CH, Geschwind JF and Thuluvath PJ: The outcome of liver transplantation in patients with hepatocellular carcinoma in the United States between 1988 and 2001: 5-year survival has improved significantly with time. J Clin Oncol 21: 4329-4335, 2003.

3. Sala M, Fuster J, Llovet JM, Navasa M, Solé M, Varela M, Pons F, Rimola A, García-Valdecasas JC, Brú C, et al: High pathological risk of recurrence after surgical resection for hepatocellular carcinoma: an indication for salvage liver transplantation. Liver Transpl 10: 1294-1300, 2004.

4. Hoshida Y, Villanueva A, Kobayashi M, Peix J, Chiang DY, Camargo A, Gupta S, Moore J, Wrobel MJ, Lerner J, et al: Gene expression in fixed tissues and outcome in hepatocellular carcinoma. New Engl J Med 359: 1995-2004, 2008.

5. Parisi S, Passaro F, Aloia L, Manabe I, Nagai R, Pastore L and Russo T: Klf5 is involved in self-renewal of mouse embryonic stem cells. J Cell Sci 121: 2629-2634, 2008.
6. Saxena NK, Sharma D, Ding X, Lin S, Marra F, Merlin D and Anania FA: Concomitant activation of the JAK/STAT, PI3K/AKT, and ERK signaling is involved in leptin-mediated promotion of invasion and migration of hepatocellular carcinoma cells. Cancer Res 67: 2497-2507, 2007.

7. Dong JT and Chen C: Essential role of KLF5 transcription factor in cell proliferation and differentiation and its implications for human diseases. Cell Mol Life Sci 66: 2691-2706, 2009.

8. Bartel DP: MicroRNAs: Genomics, biogenesis, mechanism, and function. Cell 116: 281-297, 2004.

9. Zhang B, Pan X, Cobb GP and Anderson TA: MicroRNAs as oncogenes and tumor suppressors. Dev Biol 302: 1-12, 2007.

10. Zimmerman AL and Wu S: MicroRNAs, cancer and cancer stem cells. Cancer Lett 300: 10-19, 2011.

11. Esquela-Kerscher A and Slack FJ: Oncomirs-microRNAs with a role in cancer. Nat Rev Cancer 6: 259-269, 2006.

12. Chen X, Ba Y, Ma L, Cai X, Yin Y, Wang K, Guo J, Zhang Y, Chen J, Guo X, et al: Characterization of microRNAs in serum: A novel class of biomarkers for diagnosis of cancer and other diseases. Cell Res 18: 997-1006, 2008.

13. Cao T, Li H, Hu Y, Ma D and Cai X: miR-144 suppresses the proliferation and metastasis of hepatocellular carcinoma by targeting E2F3. Tumor Biol 35: 10759-10764, 2014.

14. Ludwig JA and Weinstein JN: Biomarkers in cancer staging, prognosis and treatment selection. Nat Rev Cancer 5: 845-856, 2005.

15. Calin GA and Croce CM: MicroRNA signatures in human cancers. Nat Rev Cancer 6: 857-866, 2006.

16. Furuta M, Kozaki KI, Tanaka S, Arii S, Imoto I and Inazawa J: miR-124 and miR-203 are epigenetically silenced tumor-suppressive microRNAs in hepatocellular carcinoma. Carcinogenesis 31: 766-776, 2009.

17. Ozen M, Karatas OF, Gullluoglu S, Bayrak OF, Sevli S, Guzel E, Ekici ID, Caskurlu T, Solak M, Creighton CJ and Ittmann M: Overexpression of miR-145-5p inhibits proliferation of prostate cancer cells and reduces SOX2 expression. Cancer Invest 33: 251-258, 2015.

18. Noh JH, Chang YG, Kim MG, Jung KH, Kim JK, Bae HJ, Eun JW, Shen Q, Kim SJ, Kwon SH, et al: MiR-145 functions as a tumor suppressor by directly targeting histone deacetylase 2 in liver cancer. Cancer Lett 335: 455-462, 2013.

19. Yuen MF, Hou JL and Chutaputti A; Asia Pacific Working Party on Prevention of Hepatocellular Carcinoma: Hepatocellular carcinoma in the Asia pacific region. J Gastroenterol. Hepatol 24: 346-353, 2009.

20. Iliopoulos D, Satra M, Drakaki A, Poultsides GA and Tsezou A: Epigenetic regulation of hTERT promoter in hepatocellular carcinomas. Int J Oncol 34: 391-399, 2009.

21. Milazzo M, Fornari F and Gramantieri L: MicroRNA and hepatocellular carcinoma: Biology and prognostic significance. Minerva Gastroenterol Dietol 57: 257-271, 2011.

22. Avgeris M, Stravodimos K, Fragoulis EG and Scorilas A: The loss of the tumour-suppressor miR-145 results in the shorter disease-free survival of prostate cancer patients. Br J Cancer 108: 2573-2581, 2013.

23. Sanfiorenzo C, Ilie MI, Belaid A, Barlési F, Mouroux J, Marquette $\mathrm{CH}$, Brest $\mathrm{P}$ and Hofman P: Two panels of plasma microRNAs as non-invasive biomarkers for prediction of recurrence in resectable NSCLC. PLoS One 8: e54596, 2013.

24. Schee K, Lorenz S, Worren MM, Günther CC, Holden M, Hovig E, Fodstad O, Meza-Zepeda LA and Flatmark K: Deep sequencing the microRNA transcriptome in colorectal cancer. PLoS One 8: e66165, 2013.

25. Tong D, Czerwenka K, Heinze G, Ryffel M, Schuster E, Witt A, Leodolter $S$ and Zeillinger R: Expression of KLF5 is a prognostic factor for disease-free survival and overall survival in patients with breast cancer. Clin Cancer Res 12: 2442-2448, 2006.

26. Bateman NW, Tan D, Pestell RG, Black JD and Black AR: Intestinal tumor progression is associated with altered function of KLF5. J Biol Chem 279: 12093-12101, 2004.

27. Yang Y, Goldstein BG, Chao HH and Katz JP: KLF4 and KLF5 regulate proliferation, apoptosis and invasion in esophageal cancer cells. Cancer Biol Ther 4: 1216-1221, 2005.

28. Kwak MK, Lee HJ, Hur K, Park DJ, Lee HS, Kim WH, Lee KU, Choe KJ, Guilford P and Yang HK: Expression of Krüppel-like factor 5 in human gastric carcinomas. J Cancer Res Clin Oncol 134: 163-167, 2008. 